\section{Relative Susceptibility of Pecan Cultivars to Zonate Leaf Spot}

\author{
C.C. Reilly, B.W. Wood, and M.W. Hotchkiss \\ U.S. Department of Agriculture, Agricultural Research Service, Southeastern \\ Fruit and Tree Nut Laboratory, 111 Dunbar Road, Byron, GA 31008
}

Additional index words. disease, fungicide, resistance, management, production, Carya illinoinensis

\begin{abstract}
Zonate leaf spot (ZLS) [Cristulariella moricola (Hino) Redhead (C. pyramidalis Waterman and Marshall)] on pecan [Carya illinoinensis (Wangenh.) K. Koch.]—associated with unusually wet weather during June, July, and August-occurred across much of Georgia during Summer 1994. Scott-Knott cluster analysis indicated that 27 of 36 evaluated genotypes exhibited little or no field susceptibility to ZLS. 'Moneymaker' exhibited the greatest susceptibility of all cultivars studied, with 'Cape Fear', 'Elliott', 'Sumner', and 'Sioux' segregating to exhibit moderate susceptibility. An evaluation of commercial orchards indicated susceptibility of major southeastern cultivars as 'Desirable' < 'Stuart' < 'Schley' > 'Moneymaker'. Control of ZLS in commercial orchards using standard fungicide spray strategies appeared to be generally ineffective.
\end{abstract}

Unusually wet weather throughout much of Georgia during Summer 1994 initiated a rare outbreak of zonate leaf spot (ZLS) on pecan. For example, at Byron, Ga., rainfall during June, July, and August was, respectively, $156 \%, 422 \%$, and $120 \%$ higher than the 20 -year average. Favorable conditions for disease development include prolonged periods of moisture, especially in crowded orchards. The disease is usually detected first in low areas within the orchard or on border trees near forests or swamps (Bertrand, 1984; Latham, 1972). All pecan cultivars are presently assumed to be susceptible to ZLS, but to our knowledge, little is known of the relative degree of susceptibility (Bertrand, 1984; Latham, 1991). This study reports a comparison of the susceptibility of several genotypes of pecan to C. moricola under field conditions during an outbreak initiated by the excessive rainfall during the 1994 growing season. Relative ratings of ZLS also are reported for leading cultivars in commercial orchards in which fungicides were used for ZLS control.

\section{Materials and Methods}

The test orchard was comprised of 32 cultivars and four advanced hybrids. Trees were growing in a 6.4-ha orchard in a randomized complete-block planting with three blocks having one tree per block. Trees were 23 years

Received for publication 13 Oct. 1995. Accepted for publication 28 May 1996. Names are necessary to report factually on available data; however, the U.S. Dept. of Agriculture (USDA) neither guarantees nor warrants the standard of the product, and the use of the name by USDA implies no approval of the product to the exclusion of that to others that may also be available. The cost of publishing this paper was defrayed in part by the payment of page charges. Under postal regulations, this paper therefore must be hereby marked advertisement solely to indicate this fact. old and growing at a spacing of $18.5 \times 18.5 \mathrm{~m}$. Trees were nonirrigated and no fungicides were applied to the orchard during the 1994 season. Commercial orchards near Albany, Ga., also were evaluated for cultivar differences in ZLS susceptibility. At least 40 trees of 'Stuart', 'Desirable', 'Moneymaker', and 'Schley' were rated in each of three orchards and an average rating calculated for the cultivars. The rating scale for ZLS in both studies was $1=$ no disease; $2=$ light (few lesions widely scattered within the lower canopy); $3=$ medium (lesions obvious and clustered in the lower canopy); 4 = heavy (zonate leaf spot throughout the tree); and 5 = very heavy (most leaves infected and leaf drop obvious).

The relative susceptibility of the 36 genotypes were analyzed with the SAS System GLM procedure (SAS Inst., 1985) with cultivar separation by Scott-Knott cluster analysis (Willavize et al., 1980). Only 1994 data are reported because of the rarity of ZLS occurrence. This disease had not been observed at the test site in at least the past 10 years and is uncommon throughout the southeastern United States.

\section{Results and Discussion}

ZLS symptoms of the 1994 outbreak were the same as described by Latham (1969). Lesions on the upper side of leaflets were grayish-brown with faintly visible concentric darker brown rings. Viewed from the abaxial surface of the leaf, lesions were light brown to tan and the darker brown concentric rings were obvious. Small lesions were typically circular but became somewhat irregular as they developed. On severely infected leaves, the lesions coalesced, giving a dried appearance that caused the leaflet to curl upward from the margin and then eventually abscise. The fungal fruiting bodies are cone- or pyramid-shaped structures (macroconidia) visible on developing lesions during periods of free moisture or high humidity.
The levels of ZLS susceptibility of the 36 pecan genotypes (Table 1) separated into three distinct groups (no or low incidence, medium to heavy, and heavy to very heavy). Only nine of the 36 genotypes were in the medium to heavy and heavy to very heavy groupings. 'Cape Fear', 'Elliott', 'Sumner', and 'Sioux', commonly cultivated cultivars in the southeastern United States, were rated medium to heavy for ZLS susceptibility. 'Pawnee', 'Caddo', 'Farley', and 'Curtis' are likely among the most resistant. 'Moneymaker' was the most severely affected of all cultivars rated.

Relative susceptibility to ZLS of mature 'Desirable', 'Stuart', 'Schley', and 'Moneymaker' trees, the dominant cultivars in Georgia, was determined in commercial orchards with mixed cultivars. 'Moneymaker' trees were defoliating in early September, whereas associated 'Schley' and 'Stuart' trees were less severely affected. 'Schley' was more susceptible than 'Stuart'. In contrast, 'Desirable' had a consistently low rating for the disease in all orchards visited. Thus, the evaluation of commercial orchards indicated that susceptibility to ZLS of major southeastern

Table 1. Scott-Knott cluster analysis of relative levels of zonate leaf spot susceptibility among 36 pecan genotypes.

\begin{tabular}{|c|c|c|}
\hline Cultivar & $\begin{array}{c}\text { Disease } \\
\text { rating }\end{array}$ & $\begin{array}{c}\text { Susceptibility } \\
\text { class }^{\mathrm{z}}\end{array}$ \\
\hline Apache & 1 & $\mathrm{~N}-\mathrm{L}$ \\
\hline Cherokee & 1 & $\mathrm{~N}-\mathrm{L}$ \\
\hline Cheyenne & 1 & $\mathrm{~N}-\mathrm{L}$ \\
\hline Chickasaw & 1 & $\mathrm{~N}-\mathrm{L}$ \\
\hline Moore & 1 & $\mathrm{~N}-\mathrm{L}$ \\
\hline Osage & 1 & $\mathrm{~N}-\mathrm{L}$ \\
\hline Pawnee & 1 & $\mathrm{~N}-\mathrm{L}$ \\
\hline Riverside & 1 & $\mathrm{~N}-\mathrm{L}$ \\
\hline Shawnee & 1 & $\mathrm{~N}-\mathrm{L}$ \\
\hline Shoshoni & 1 & $\mathrm{~N}-\mathrm{L}$ \\
\hline Caddo & 1.3 & $\mathrm{~N}-\mathrm{L}$ \\
\hline Houma & 1.3 & $\mathrm{~N}-\mathrm{L}$ \\
\hline Farly & 1.3 & $\mathrm{~N}-\mathrm{L}$ \\
\hline Kiowa & 1.3 & $\mathrm{~N}-\mathrm{L}$ \\
\hline Cowley & 1.5 & $\mathrm{~N}-\mathrm{L}$ \\
\hline Candy & 1.7 & $\mathrm{~N}-\mathrm{L}$ \\
\hline Curtis & 1.7 & $\mathrm{~N}-\mathrm{L}$ \\
\hline Grabohls & 1.7 & $\mathrm{~N}-\mathrm{L}$ \\
\hline Stuart & 1.7 & $\mathrm{~N}-\mathrm{L}$ \\
\hline Western Schley & 1.7 & $\mathrm{~N}-\mathrm{L}$ \\
\hline Mahan & 2.0 & $\mathrm{~N}-\mathrm{L}$ \\
\hline Mohawk & 2.0 & $\mathrm{~N}-\mathrm{L}$ \\
\hline Oconee & 2.0 & $\mathrm{~N}-\mathrm{L}$ \\
\hline Success & 2.0 & $\mathrm{~N}-\mathrm{L}$ \\
\hline Wichita & 2.0 & $\mathrm{~N}-\mathrm{L}$ \\
\hline Barton & 2.5 & $\mathrm{~N}-\mathrm{L}$ \\
\hline Choctaw & 2.5 & $\mathrm{~N}-\mathrm{L}$ \\
\hline $61-6-28$ & 3.0 & $\mathrm{M}-\mathrm{H}$ \\
\hline Cape Fear & 3.0 & $\mathrm{M}-\mathrm{H}$ \\
\hline Elliott & 3.0 & $\mathrm{M}-\mathrm{H}$ \\
\hline Sumner & 3.3 & $\mathrm{M}-\mathrm{H}$ \\
\hline $40-9-297$ & 3.5 & $\mathrm{M}-\mathrm{H}$ \\
\hline Sioux & 3.7 & $\mathrm{M}-\mathrm{H}$ \\
\hline Moneymaker & 4.3 & $\mathrm{H}-\mathrm{VH}$ \\
\hline $58-4-25$ & 4.5 & $\mathrm{H}-\mathrm{VH}$ \\
\hline $63-5-43$ & 5.0 & $\mathrm{H}-\mathrm{VH}$ \\
\hline
\end{tabular}

${ }^{\text {zSusceptibility classes separated by Scott-Knott clus- }}$ ter analysis into three groups $(\alpha \leq 0.05): \mathrm{N}-\mathrm{L}=$ no disease to low; $\mathrm{M}-\mathrm{H}=$ medium to heavy; $\mathrm{H}-\mathrm{VH}=$ heavy to very heavy incidence. 
cultivars is 'Desirable' < 'Stuart' < 'Schley' < 'Moneymaker', with field ratings of 2.0, 3.0, 4.0 , and 5.0, respectively.

Fungicide treatments were applied in the commercial orchards evaluated specifically to control ZLS when the disease first appeared; however, according to the orchard managers, the disease continued to develop. Additional information on disease control is needed regarding fungicide efficacy and application timing.

These data indicate that several cultivars appear to possess resistance to ZLS. However, many of the genotypes in the "no to low disease" category might express higher levels of susceptibility under slightly different con- ditions. An example is 'Stuart', which in the large genotype study was rated as 1.7 , whereas it was rated as 3.0 in commercial orchards. This difference may be caused by differences in orchard wetness periods between the two locations. Several of the important commercial cultivars are fairly susceptible. While further information is needed to accurately assess the true resistance of pecan genotypes to ZLS, these data present for the first time quantitative comparisons of the relative susceptibilities of pecan cultivars and provides information that could influence decisions as to which cultivars to plant in very wet environments or where orchards are near forests or swamps.

\section{Literature Cited}

Bertrand, P. 1984. Zonate leaf spot, p. 38-39. In Pecan pest management in the Southeast. Univ. of Georgia Agr. Ext. Sta. Bul. MP176.

Latham, A.J. 1969. Zonate leaf spot of pecan caused by Cristulariella pyramidalis. Phytopathology 59:103-107.

Latham, A.J. 1972. Some hosts of Cristulariella pyramidalis in pecan orchard hedgerows. Plant Dis. Rptr. 56:176-177.

Latham, A.J. 1991. Zonate leaf spot of pecan: A review and research needed, p. 98-100. In: B.W. Wood and J.A. Payne (eds.). Proc. First Natl. Pecan Workshop Pecan Husbandry: Challenges and opportunities. ARS-96.

SAS Institute. 1985. SAS user's guide: Statistics. version 5 ed. SAS Inst., Cary, N.C.

Willavize, S.A., S.G. Carmer, and W.M. Walker. 1980. Evaluation of cluster analysis for comparing treatment means. Agron. J. 72:317-320. 